\title{
Enhancement of Power Quality in a Grid Integrated WECS with Shunt Voltage Controller
}

\author{
Dr.K.Veeresham ${ }^{1}$, Lade Abhinandh ${ }^{2 *}$, Dr.B. Neelakanteshwarrao ${ }^{1}$ \\ ${ }^{1}$ Associate Professor VNRVJIET, Hyderabad \\ 2 Student VNRVJIET, Hyderabad
}

\begin{abstract}
This paper deals with study of wind energy conversion system when it is interconnected with the grid. Main objective of the paper is to improve the quality of the power when wind energy system is linked with the non-linear loads. In this work DSTATCOM (FACTS Device) is used as a shunt active controller which used to reduce harmonics, when grid is interconnected with the non-linear load. In this work a new methodology is proposed i.e., Fuzzy Logic technique is integrated in the control circuit of DSTATCOM that helps to compare the reference voltage and output voltage of grid in order to minimize the error and improve power quality
\end{abstract}

\section{Introduction}

\subsection{Introduction to Wind energy}

Electrical energy has become so important in modern day life, such that it has become one of the basic needs of human life. Electrical energy is produced through conventional way such as burning of coal, harnessing the potential energy of water, trapping the kinetic energy of a moving atomic particle as in Nuclear energy conversion, but owing to the scarcity of the fuel inputs of above mentioned processes there is parading shift in the means of production of electrical energy in the recent years which are known as Non-conventional energy sources. Few examples to that are solar, wind, biomass and geothermal etc.. Out of these Non-conventional energy sources, wind energy is potential source because of its free availability, cleaner operation and relatively low cost operation. The major challenge in Win Energy Conversion System (WECS)is the highly randomized availability of wind, because of which sophisticated and precision controllers are required to provide seamless continuous and quality power. This paper proposes such controller based on DSTATCOM scheme which will minimize harmonic content greatly.

\subsection{Grid interfaced by wind energy conversion system (WECS)}

In this project, conventional grid is interfaced with the wind energy and system control scheme is provided with the help of fuzzy logic circuit.
Since, from recent years DFIG is observed a specific importance in wind power production this is because it has capability to handle only a fraction of power from the total systems power. It is possible because the induction machine is integrated with power electronic equipment (VSC). Since DFIG handling fraction of systems power losses in power equipment are reduced [2]. Moreover, cost is also reduced due to usage of small converter. The major limitation of DFIG is starting problem, oscillatory transients, synchronization and control circuit of DFIG is complex compared with control circuit of standard induction machine[3][4].

In this work, fuzzy control methodology is proposed for the control of DFIG here fuzzy control technique is used to compare the reference voltage and stator voltage of generator. Vector control has been implemented in dq reference frame on rotor side for control of reactive and active power. In order to synchronize stator voltage of DFIG with grid voltage phase locked loop is used. The additional advantage of PLL is to control the output frequency this enables the synchronized voltage to smoothly connect to the load.

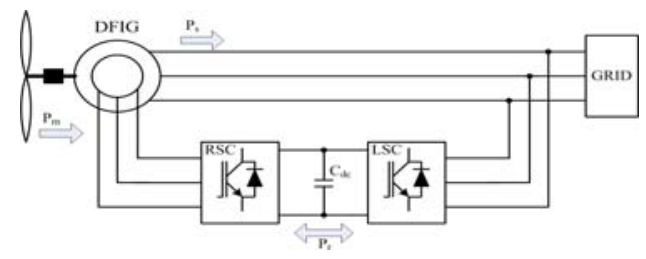

Fig: 1 DFIG system configuration

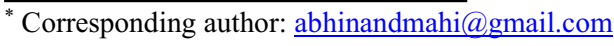




\section{System configuration}

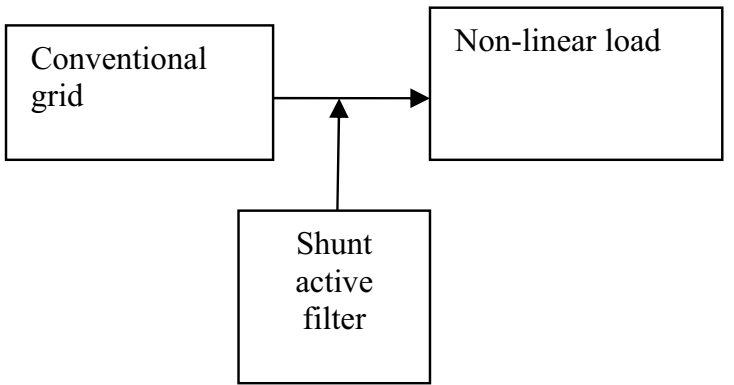

Fig: 2 Basic system configuration with shunt active filter

In this project one of the voltage source converter (VSC1) is connected to the stator winding of DFIG, main function of this converter is to collect the output voltage of the DFIG. In this voltage source converter (VSC1) fuzzy logic controller is used compare the reference voltage and output voltage of the stator. Here reference voltage is obtained from the DC link. This DC link is also used as a source to another voltage source converter (VSC2) whose function is to control the rotor speed [5]. For this voltage source converter (VSC2) the control circuit is fuzzy logic controller. In this VSC2 the controller circuit compares the reference voltage which is obtained from DC link and the output voltage from the wind whose output is fed to rotor circuit of the DFIG [6].

In this voltage source converter $(1 \& 2)$ abc to dq0 transformation is used in order to provide 90 degrees phase shift and obtain stationary frame from the rotatory frame. Here Pulse Generator is used in each converter to transform abc to $\alpha \boldsymbol{\beta}$ parameters and generate required pulses to the converter (Parks transformation).

\subsection{Determination Factor}

It is used to convert analog to digital signal with the help of switching table. Here plane $(\boldsymbol{\alpha}, \boldsymbol{\beta})$ is divided into 12 sectors to achieve digital signal.

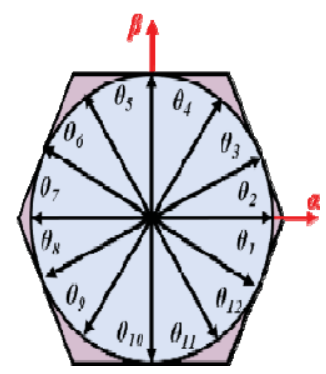

Fig: 3 Representation of plane ( $\boldsymbol{\alpha}, \boldsymbol{\beta})$ divided in to 12 sectors
The following equations will represent the sector determination

$$
(N-2) \frac{\pi}{6}<\theta_{N}<(N-1) \frac{\pi}{6}
$$

Where $\mathrm{N}=1,2,3 \ldots 12$ is the number of the sector.

$$
\theta=\operatorname{Arctg}\left(\frac{V_{\beta}}{V_{\alpha}}\right)
$$

\subsection{Fuzzy logic controllers}

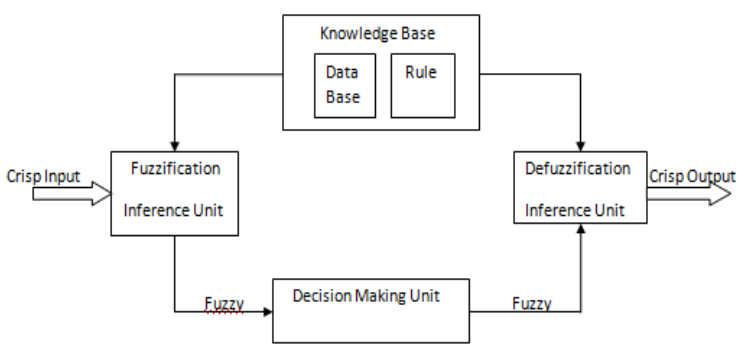

Fig 4: Representation of fuzzy logic controller

In this paper we are using fuzzy controller instead of conventional PI controller. In the PI controller it has only two stable states i.e., either 1 or 0 on the other hand the advantage of the fuzzy controller system is that it analyses analog input values in terms of logical variables that takes on continuous value between 0 and 1 contrast to digital logic.

\section{Simulink Model:}

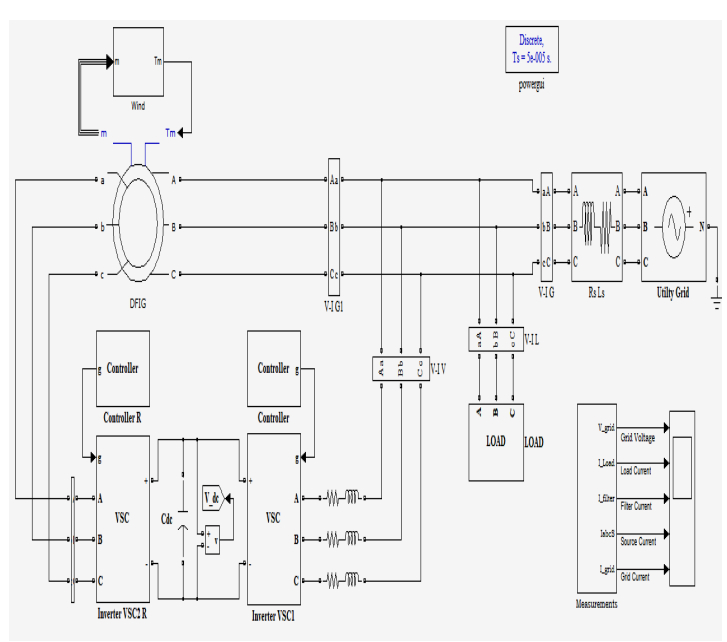

Fig.5. Simulink model of proposed network 
The wind speed is considered up to time $\mathrm{t}=0.6 \mathrm{~s}$ as $7 \mathrm{~m} / \mathrm{sec}$ and transient wind speed variation is considered between time $0.6 \mathrm{~s}$ to $1 \mathrm{sec}$ as $8 \mathrm{~m} / \mathrm{s}$. the obtained simulation response is explored in fig.6

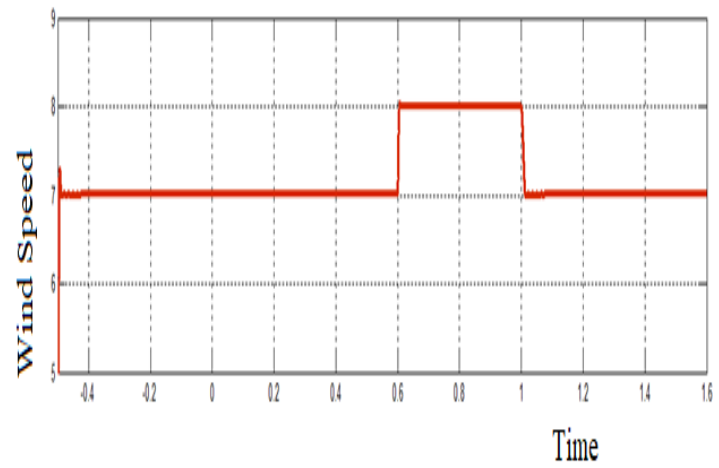

Fig.6. DFIG Wind speed

The simulation response of velocity of wind corresponding wind speed variation is represented in Fig.7

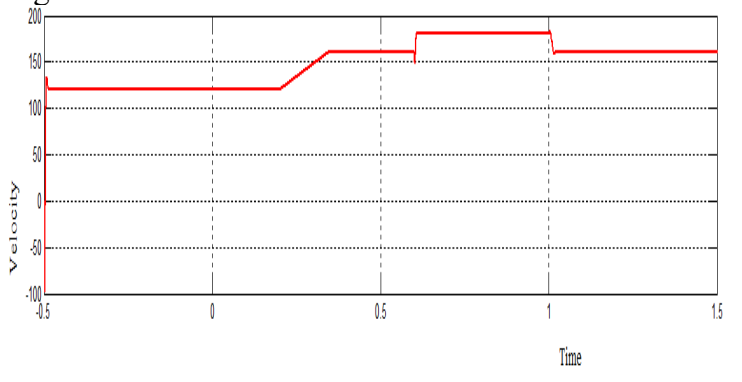

Fig.7. DFIG Wind Velocity

Fig. $8 \mathrm{a}$ and $8 \mathrm{~b}$ illustrates the load voltage and load currents simulation responses, Time period of $0.1 \mathrm{secs}$ to 0.2 secs, unbalanced load is considered (one phase removed from the load) even this unbalanced load condition also steady state load voltage is obtained.

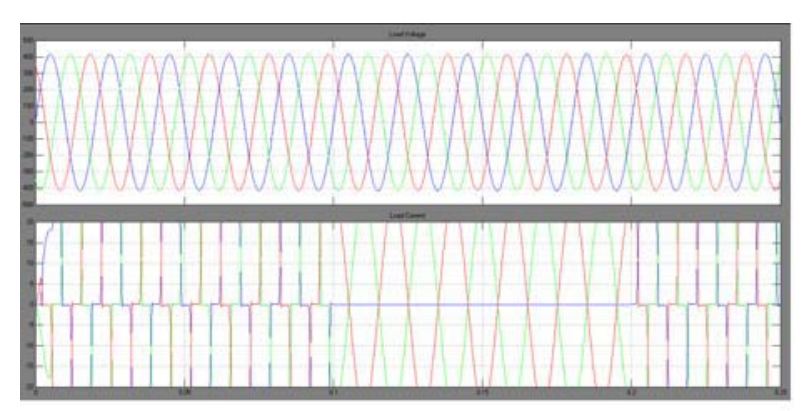

Fig 8a. Output wave forms of Load current and Load voltage

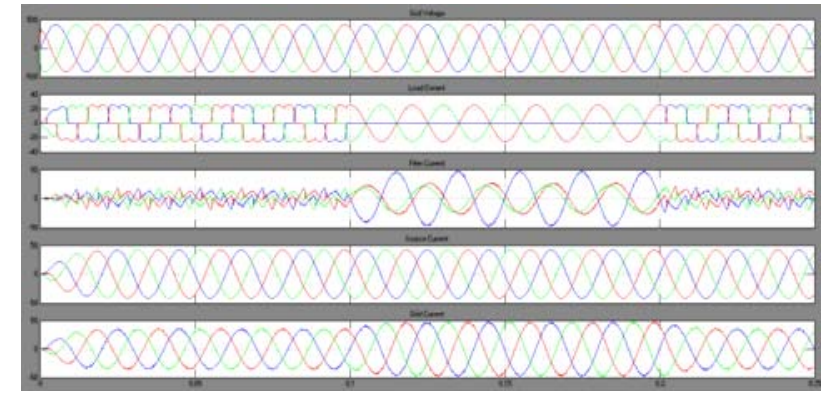

Fig.8b. Output wave forms of Filter current and voltage current waveforms (Load \& Grid)

\subsection{Results and analysis:}

From the above representations we can show the variation in the Load current profile that is due to nonlinearity in load. As we discussed previously that the main objective of the project is to minimize the harmonic content in the grid integrated wind energy system with the implementation of the control circuit. In the THD analysis that is represented below we can prove that the harmonic content (Total Harmonic Distortion) is reduce to below 5\%. To achieve this DSTATCOM is used as shunt active filter which is shown in the schematic representation of simulation model (Fig.5). There are many techniques are implemented previously to reduce harmonics, a part from that in this work a new approach has been implemented that is fuzzy controller. Generally in conventional method of approach PI control will be there to compare the reference value and to reduce error it will be used. But the major advantage while going fuzzy controller time taking to the reduce error is less. In this work Load current and Load voltage parameters are maintained constant by implementing this shunt active filter which is connected across the DFIG.

\subsubsection{THD Analysis:}

Total Harmonic Distortion before placing Controller:

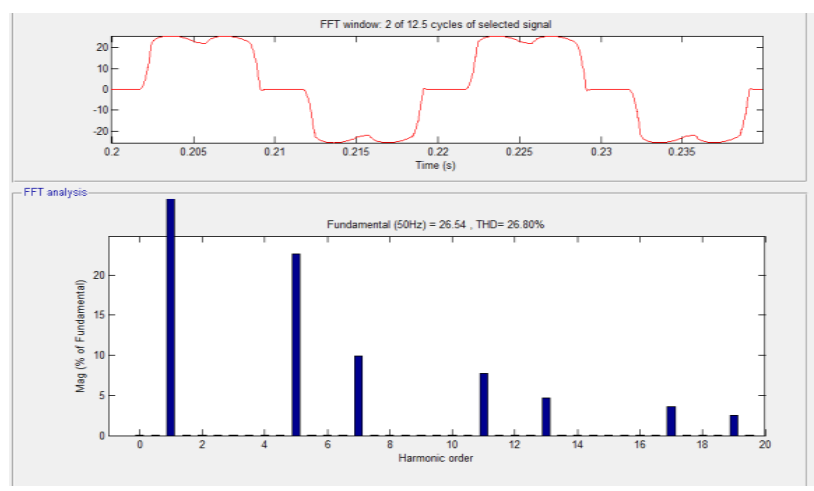

Fig. 9aTHD Analysis before placing Controller 
Total Harmonic distortion after placing the Controller:

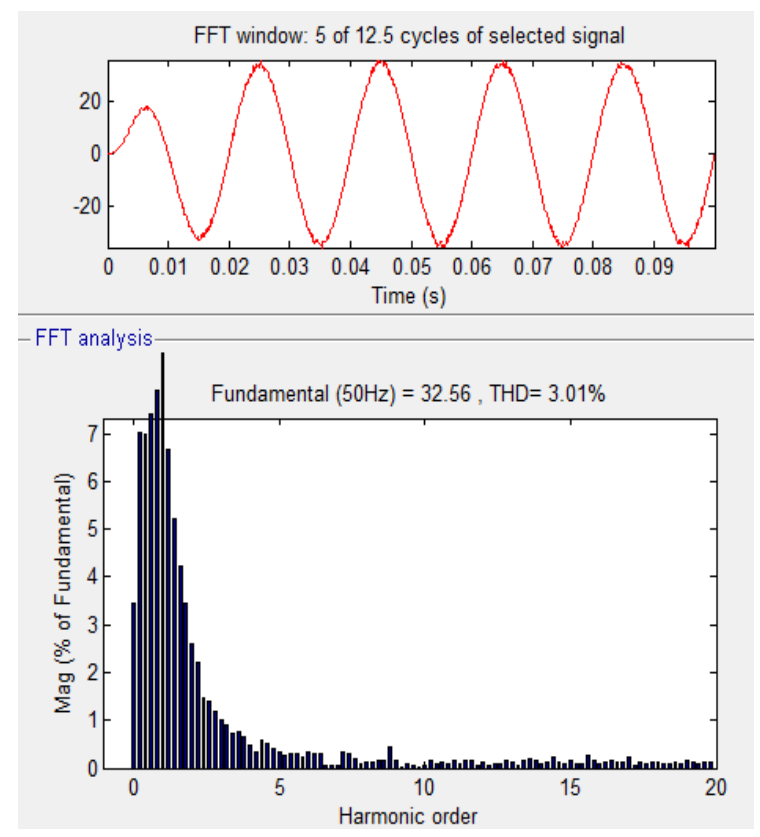

Fig. 9b THD Analysis after placing Controller

From the above shown graph it can be concluded that by implementing the Shunt Active Filter (DSTATCOM) in the grid interconnected wind energy conversion system the total harmonic distortion is reduced from $26.80 \%$ to below $5 \%$ that is $3.01 \%$.

\section{Conclusion:}

From the obtained simulation results it is evident that even with wind variations and unbalanced load conditions which are very frequent in a real time power system the grid will be able to maintain steady output voltage at the load terminals with application of proposed technique. Along with the steady output voltage the harmonics which are present in current waveform are also greatly reduced using shunt active filter (DSTATCOM). The use of DSTATCOM is also economically viable considering the effects of fluctuations and harmonics in supply voltage and current which are significantly reduced using the above proposed technique.

\section{References:}

1. Joshi N, Mohan N., "A Novel Scheme to connect wind Turbines to the Power Grid", IEEE Transactions on Energy Conversion, 24(2),504-510, 2009.

2. Ab-Khalil A, Lee D., LEE S., "Grid connection of Doubly-fed Induction Generators in Wind energy conversion system".
3. A.Chaoui., J. Gaubert, F. Karim, "Power quality improvement using DPC controlled three-phase shunt active filter", Electric power systems Reasearch, vol 80, pp 657-666, 2010.

4. Malinwoski, M., et al, "A comparative study of control techniques for PWM rectifiers in AC adjustable speed drives", IEEE Transactions on industrial electronics, 18(6), pp, 1390-1396, 2003.

5. K.Bala Nikilesh, P.Nageswara Rao "Harmonic Compensation using D-Statom in Combination with Renewable Energy Sources to enhance Power Quality", IEEE Jan 2015.

6. kaluppan p.kamala kanta mahapatra " $P L L$ Synchronisation with PID Controller Based Shunt Active Power Line Conditioner" IJCEE vol.3, No.1, Feb 2011.

7. S.k tiwari, B.singh and P.K. Goel "Design an control of micro grid fed by renewable energy sources" 2016 IEEE $6^{\mathrm{TH}}$ Inter. Conference on power systems (ICPS), New Delhi 2016.pp1-6.

8. S.Heier, Grid integration of wind energy conversion system. Hoboken, NJ, Wiley 1998.

9. A,B. Rey boue, R Garcia-Valvarde, F de A rus vila and jose M. Torrelo-ponse, "An integrative approach to the design methodology for 3-phase power conditioners in photovoltaic grid connected systems". Energy conversion an management vol 56 pp 80-95, Dec 2018. 10. H.polinder F.F.A van der prijl , G.jde vilder and p.Tanver " Compariion of direct drive and geared generator concepts for wind turbines", IEEE international conference of electric machines and drives, 2016., Sam Antonio, TX, 2016,PP543-550. 